\title{
Dialect as a Marker of Political Orientation
}

\author{
Natalia Knoblock* \\ LSA Annual Meeting 2014, Minneapolis, January 2-5, 2014
}

1. Introduction. Social psychologists, sociolinguists, and linguistic anthropologists have long recognized that people are categorized and judged by the way they speak. Language attitude studies (e.g., Lambert et al. 1960) examined how the listeners perceived the speakers' social identity based on the accent or the variety of the language used. Analysis of the responses to language varieties led to findings that some varieties are valued along measures of solidarity while others are valued for status (e.g. Ryan, Giles \& Sebastian 1982, Preston \& Niedzielski 2009). Research also shows that speech perception does not depend purely on physical factors, but also on listeners' expectations based of sociological factors. For example, Niedzielski (1999) determined that vowel perception in south-eastern Michigan depended on whether the speaker was a introduced as a fellow Detroiter or as a foreigner. Koops, Gentry \& Pantos (2008) found significant effects of perceived speaker age on speech perception in Texas. Some studies also examined the link between dialect perception and political ideology. Labov (2010), for instance, found a possible association between political views and the Inland North dialect. Hall-Lew, Coppock, \& Starr (2010) in the analysis of the "liberal vowel" in the word "Iraq" argued that phonological variables are a potential resource for the expression of political identity. Schrimpf (2013) found that people in Tennessee who voted Republican showed stronger effects of the Southern Vowel Shift than the participants who voted for a Democrat. This exploratory project continues the line of research that examines a correlation between dialect and political orientation judgment, but moves the focus of attention from language production to perception.

2. Hypothesis. We suggest that people presuppose a correlation between local dialects and prevalent political views, and that the population of a largely conservative area will assume that people who speak the same dialect are more conservative as well.

3. Background. The experiment was conducted in the Huron County of Michigan, a rural, traditionally conservative area in the "Thumb" of Michigan. The county consistently elects Republican local officials and the presidential voting results show that the locale votes more conservative than the state overall. For example, in the last three presidential elections when the state of Michigan voted for Democratic candidates, twice (in 2012 and 2004) the county voted for the Republican contender, and once (in 2008) gave a very narrow advantage to the Democrat instead of a landslide victory he enjoyed in the rest of the state.

4. Method. To check our hypothesis we collected speech samples from four Michigan residents. They were all female, under the age of 50, and spoke with slightly different accents. One was a local person who lived all her life in Huron County and exhibited some features of Northern Cities Chain Vowel Shift (NCCS), the other was from Saginaw, MI and also spoke with a NCCS accent; there was also an AfricanAmerican Vernacular English (AAVE) speaker, and a first-generation immigrant, a Ukrainian-American, whose pronunciation showed some influence of her Slavic background. They were asked to read an article from a local newspaper, neutral in content. Their speech samples were analyzed with PRAAT, and then used to isolate several words that were presented to the study subjects.

The experiment included 27 respondents from Huron County, 13 male, 14 female. The participants were also asked to share such demographic data as age, educational level, whether or not

*Author: Natalia Knoblock, Saginaw Valley State University (nlknoblo@svsu.edu). 
they have been a Huron County resident, lived outside of the county for more than 10 years, and whether their parents had been Huron County residents as well. Additionally, after survey completion, the participants we asked to rate themselves on the same scales they used for the speakers, which provided us with another important variable - their self-reported liberal or conservative orientation.

We used the semantic differential technique established in the work of Osguud, Suci \& Tannenbaum (1957), but modified it according to (Niedzielski \& Preston 1999) using 6-point scales of opposites acquired from folk respondents. We asked the participants to make a judgment about some qualities of the voices they heard. They listened to four speech samples, each containing the same 25 words but read by different speakers and were asked to rate the speakers on a number of aspects including "liberal vs. conservative". To camouflage our interest in that particular aspect, we placed it among other scales, such as friendly-unfriendly, honest-dishonest, strong-weak, aggressive-reserved, and educated-uneducated which were included to only distract the listeners and were not considered in the subsequent analysis. Each scale had values from one to six and the subjects could mark them closer to the sides (one or six) if they felt the voice they heard exhibited those qualities strongly, or they could mark three or four if they thought the qualities were not very obvious. In either case, they were forced to make a judgment about the speaker based on the way she sounded. The results were later averaged, and the score under 3.5 meant that the person was judged somewhat liberal, while the score over 3.5 meant that the person was perceived as more conservative.

5. Results. In our experiment, the overall results did not exhibit the trend we expected. However, when they were grouped into categories according to demographic data, such variables as gender, age, residency, and self-reported liberal or conservative ideology proved to be good indicators of associating the local dialect with being more conservative.

After averaging the scores for the "liberal-conservative," we observed that female respondents fit the predicted pattern better than males: their average self-evaluation score for "liberal-conservative" was 4.44 unsurprisingly identifying them as mostly conservative. Their evaluation of the local speaker was 3.67, Saginaw resident - 3.22, the first-generation immigrant 2.44, and AAVE speaker - 3.11, displaying the tendency to assume that the person whose dialect was closer to their own was closer to them in political orientation as well.

Another group where the same trend could be detected was the participants younger than 50 years of age. Their self-evaluation as fairly conservative was reflected in the average score of 4.42. Their evaluation of the local person was 4.14, Saginaw resident - 3.71, Ukrainian-American - 3.14, and AAVE speaker -3.28 .

The people who lived most of their lives in Huron county and did not leave it for longer than 10 years assigned themselves with an average of 4.28, local speaker - 3.61, Saginaw speaker -3.28 , the AAVE speaker -3.17 and the recent immigrant -2.83 .

Self-reported conservatives (5.24) judged the local person and Saginaw resident as closer to themselves (with 3.35 and 3.53 respectively) and the AAVE and American-Ukrainian speakers as more liberal (3.06 and 2.88).

Results displayed by self-reported liberals are close to reverse to those of the previous groups: their own score is 2.33, the local resident got 3.0, Saginaw speaker - 3.33, and AAVE and UkrainianAmerican speakers both had the average scores of 3.44. These numbers while confusing the overall averages, still can be seen as supporting our claim since the speakers who consider themselves liberal 
perceived the local person as rather liberal as well. In this case, the principle "closer in dialect - closer in political preference" still holds.

6. Conclusions. Given the small sample size of the study, it would be unwise to make far-reaching claims based on it. However, the experiment seems to support the suggestion that dialect can serve as an indicator of certain political affiliation. It can be observed that the respondents tended to assign political affiliation of speakers unfamiliar to them in line with the speakers' dialectal features and assumed that strangers whose dialect is similar to their own shared political views also similar to their own. Females fit the predicted pattern much than males, and people under 50 better than older participants. We suggest the explanation that those demographic groups were better at discerning the dialectal differences and making predictions because they were closer to the speakers in those aspects since all four of our speech sample providers were female and under 50 years of age. The speakers who have not lived outside of the county for more than 10 years also seemed to associate the local dialect with conservative, and "outsider dialects" - with more liberal orientation. Self-reported conservatives judged the local speaker somewhat more conservative than the others, and self-reported liberal leaning participants seemed to attribute their own views to the speaker who was the closest to them as well.

The study's merit is limited by the small sample size $(n=27)$, and it will benefit from accumulating more data to ensure validity of the results. Another potential area of improvement is manipulating the speech samples to equalize the timbre, pitch, and tempo of the speakers to make sure they are differentiated only by acoustics. The investigation of dialect-political identity alignment and could be used for further research focusing on more specific phonological phenomena that trigger the identification of the speaker as a liberal or as a conservative.

\section{References}

Fridland, Valerie. 2000. The Southern Shift in Memphis, Tennessee. Language Variation and Change. 11:267-285.

Hall-Lew, Lauren, Elizabeth Coppock \& Rebecca L. Starr. 2010. Indexing Political Persuasion: Variation in the Iraq Vowels. American Speech. 85.1:91-102.

Koops, Christian, Elizabeth Gentry \& Andrew Pantos. 2008. The effect of perceived speaker age on the perception of PIN and PEN vowels in Houston, Texas. University of Pennsylvania Working Papers in Linguistics 34.2: 93-101.

Labov, William. 2010. Principles of Linguistic Change, Volume 3: Cognitive and Cultural Factors. Malden, MA: WileyBlackwell.

Labov, William, Sharon Ash \& Charles Boberg. 2006. The Atlas of North American English: Phonetics, phonology and sound change. Berlin: Mouton/de Gruyter.

Lambert, Wallace E., Richard C. Hodgson, Robert C. Gardner \& Samuel Fillenbaum. 1960. Evaluational reactions to spoken language. Journal of Abnormal and Social Psychology, 60, 44-51

Niedzielski, Nancy. 1999. The effect of social information on the perception of sociolinguistic variables. Journal of Language and Social Psychology 18: 62-85.

Niedzielski, Nancy \& Dennis Preston, D. 1999. Folk Linguistics. Berlin: Mouton de Gruyter.

Osgood, Charle E.., George J. Suchi, G. \& Percy H. Tannenbaum. 1957. The measurement of meaning. Urbana, IL: University of Illinois.

Schrimpf, Natalie. 2013. Politics and dialect variation: A sociophonetic analysis of the Southern Vowel Shift in Middle TN. Retrieved from http://www.linguisticsociety.org/files/3542-6849-1-SM.pdf 